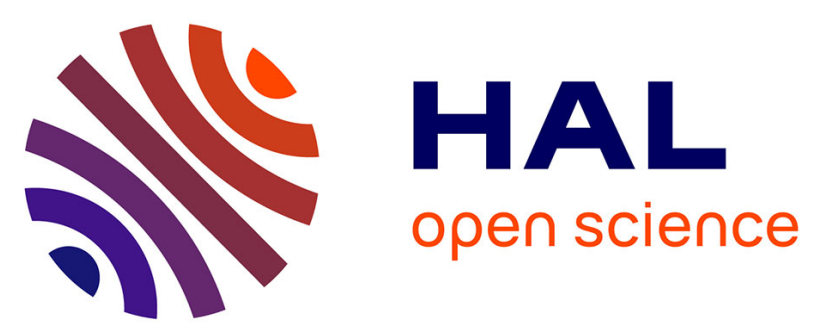

\title{
NUMERICAL SIMULATIONS TO IMPROVE THE ACCURACY OF ELECTRON-BEAM TESTING ON PASSIVATED INTEGRATED CIRCUITS
}

H. Fremont, A. Touboul, D. Gobled, Y. Danto

\section{- To cite this version:}

H. Fremont, A. Touboul, D. Gobled, Y. Danto. NUMERICAL SIMULATIONS TO IMPROVE THE ACCURACY OF ELECTRON-BEAM TESTING ON PASSIVATED INTEGRATED CIRCUITS. Journal de Physique Colloques, 1988, 49 (C4), pp.C4-149-C4-152. 10.1051/jphyscol:1988429 . jpa00227927

\section{HAL Id: jpa-00227927 https://hal.science/jpa-00227927}

Submitted on 1 Jan 1988

HAL is a multi-disciplinary open access archive for the deposit and dissemination of scientific research documents, whether they are published or not. The documents may come from teaching and research institutions in France or abroad, or from public or private research centers.
L'archive ouverte pluridisciplinaire HAL, est destinée au dépôt et à la diffusion de documents scientifiques de niveau recherche, publiés ou non, émanant des établissements d'enseignement et de recherche français ou étrangers, des laboratoires publics ou privés. 


\title{
NUMERICAL SIMULATIONS TO IMPROVE THE ACCURACY OF ELECTRON-BEAM TESTING ON PASSIVATED INTEGRATED CIRCUITS
}

\author{
H. FREMONT, A. TOUBOUL* , D. GOBLED and Y. DANTO* \\ Texas Instruments-France, BP 05, F-06270 Villeneuve Loubet, France \\ * IXL, CNRS-UA 846, Université de Bordeaux I, F-33405 Talence Cedex, \\ France
}

\begin{abstract}
RESUME : L'analyse sans contact au MEB des circuits intégrés par contraste de potentiel est non destructive. De plus, cette méthode permet par couplage capacitif L'évaluation du potentiel de pistes enfouies sous une couche isolante.

Pour augmenter la précision des mesures par cette technique, une simulation numérique en deux dimensions est utilisèe. Nous avons en particulier étudié l'influence du potentiel des pistes voisines et de la grille d'extraction, ainsi que le rôle du positionnement du faisceau sur la précision des mesures.
\end{abstract}

ABSTRACT : The Scanning Electron Microscope associated with a Voltage Contrast system is a contactless and non-destructive tool for the test of VLSI Circuits. Moreover, the potential of passivated tracks can be evaluated by Capacitive Coupling Voltage Contrast (CCVC). This paper presents a numerical simulation applied to improve the accuracy of ccvc measurements. Particularly, the role of the location of the beam, and the influence of the potential of the neighbouring tracks and of the extraction grid is studied.

\section{1 - INIRODQUCIION}

The increasing density of Integrated Circuits makes more and more necessary the development of new testing techniques for failure analysis and design validation. They must bring informations related to the internal behaviour of circuits and avoid contact problems or risks of mechanical destruction. The Electron Beam Voltage contrast in the Scanning Electron Microscope (SEM) provides these features as it is contactless and non-destructive. Moreover, the use of the Capacitive Coupling Voltage Contrast (CCVC) /1/ makes possible the measurement of the potential of tracks buried in insulating layers. Because of the multiplication of metallisation levels and because of the circuits sensitivity to a chemical depassivation, this appears of increasing interest. However, experimental tests show that some difficulties have to be overcome in order to improve the accuracy of quantitative measurements. The two main problems are the oxide charging under electron irradiation and the voltage spreading.

0xide charging mechanisms have been detailed elsewhere $12 /$. The purpose of this work is to provide a better understanding of the voltage spreading phenomenon, with the aid of 2-D numerical simulations.

\section{2 - IHEE NUMAERICAL_APPROEACH}

The voltage spreading has not to be mistaken for "Local Field Effects". Following Kohler 131 , we think that the definition, as well as the effects of the voltage spreading are different. In the "image mode" (when the beam scans the IC surface), the voltage spreading creates a potential contrast between two metallic tracks. In the "waveform mode" (when the beam is focused on a specific point), a signal can be measured in the insulator between these tracks (see photo 1). Furthermore, the extraction grid located at $6 \mathrm{~mm}$ over the IC modifies the potential of the surface.

To solve this problem, we use a two-dimensional numerical simulation of the potential distribution in test layouts which are similar to existing configurations of IC's interconnections. The extraction grid has also been taken into account. Figures 1 and 2 depict the studied structures. The differential partial equation which describes the two-dimensional potential $V(x, y)$ distribution in the structures is a Laplace's equation : $\Delta V(x, y)=0$. The potential of the different grids and the continuity of the electric induction at the oxide-vacuum interface represent the boundary conditions. $A$ finite-difference technique has been used. Hence the structure is divided up into a number 
of discrete meshes. Along the horizontal.axis, the spatial discretisation fits the diameter of the electron-beam. The calculation is iterative, and is stopped as soon as a desired precision is obtained. Typical results of these simulations are depicted in figures 1 and 2 .

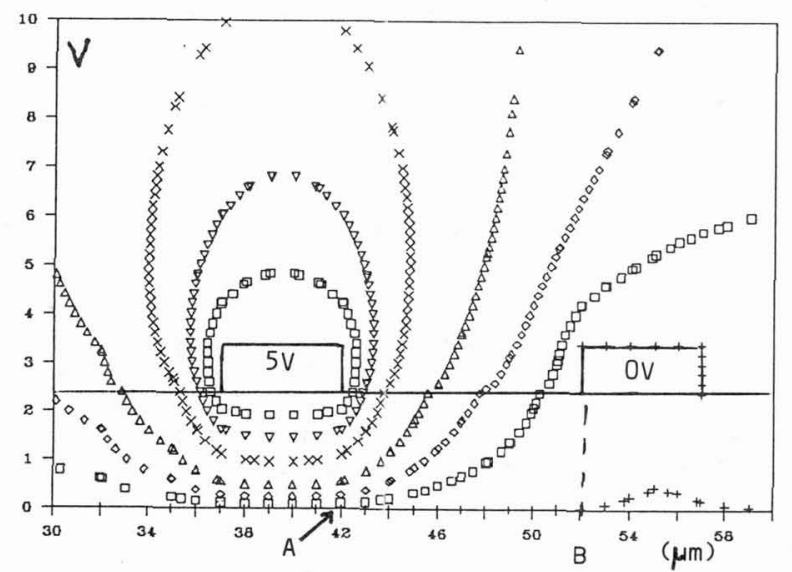

Fig. 1 : 2-grid Layout simulating the configuration of a circuit under test 口0.2V, $0.5 \mathrm{~V}, \Delta 1 \mathrm{~V}, \mathrm{x} 2 \mathrm{~V}, \nabla 3 \mathrm{~V}, \mathrm{D} 4 \mathrm{~V}$

Extraction grid potential $V e=0 \mathrm{~V}$

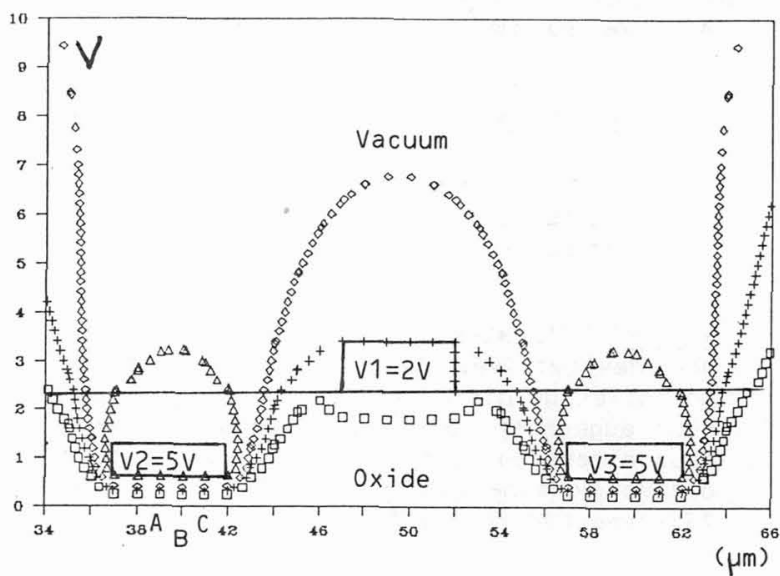

Fig._2 : Typical dimensions and equipotential lines of a 3 -grid layout D $1.5 \mathrm{~V},+2 \mathrm{~V}, \mathrm{O} 2.5 \mathrm{~V}, \Delta 4 \mathrm{~V}$

Extraction grid potential Ve $=600 \mathrm{~V}$

From the potential maps, the interface potential can be deduced. In the absence of any buried conductor (see fig. 1) there is a non-zero interface potential between the two superficial tracks. This potential can be computed and experimentally measured by the contrast potential technique.

Figure 3 shows a fair agreement between the calculated and the measured values. The slight discrepancies which can be noticed stem from the noise superimposed to the experimental data.

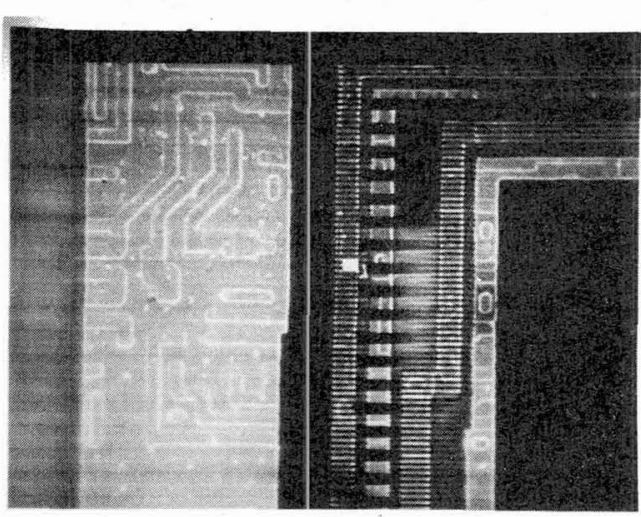

Photo 1 : Experimental evidence of the voltage spreading in the "image mode"

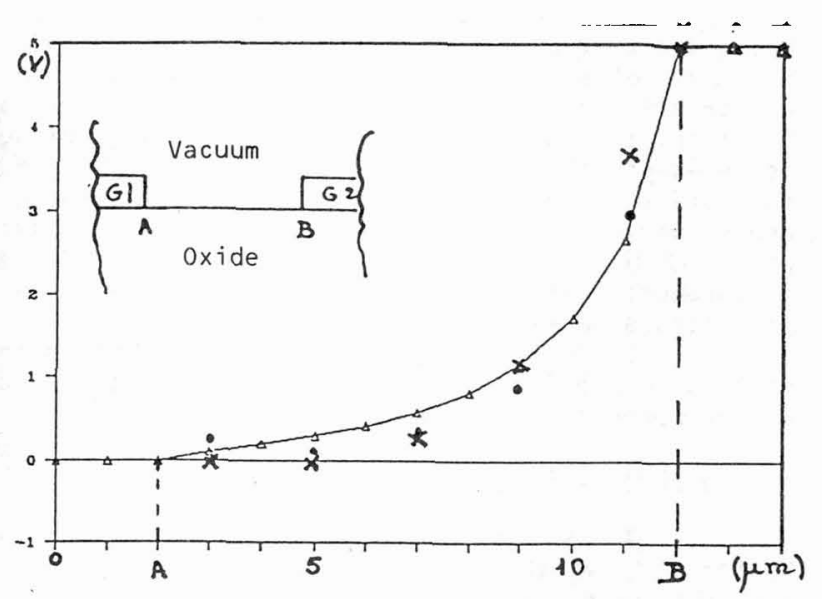

뇌._$\bar{V} 1=0 \mathrm{~V}, \mathrm{~V}_{2}$ varying from 0 to $5 \mathrm{~V}$ $\Delta:$ computed values $X: 2 \mathrm{MHz} \cdot 600 \mathrm{KHz}$ : experimental values 
When the potential of a buried track is measured with the aid of the CCVC technique (see fig. 2) the non-zero potential created at the interface by the neighbouring tracks modifies the surface potential, which causes measurement errors. Both the CCVC experimental data and the numerical simulations give an information on the interface potential, as a function of the buried, the superficial, and the extraction grids potentials. But the capacitive coupling between the buried track and the virtual electrode created by the electron beam has not been taken into account for the potential calculation. However, it will be shown that this numerical approach can still be used to improve the measurements.

\section{3 - ANALYSISI__OE_IHE_RESULIS____APPLICAIION_IO_IHE_EXPEERIMENIAL_PROCEEDURE}

This approach has been applied to the structure presented on figure 2 , in order to evaluate the influence of $V 1$, and of the extraction grid polarisation ve on the interface potential Vs on the top of the buried electrode. The calculated values of Vs depend Linearly on $V 1$ (see fig 4). To perfom a measurement, the beam must be positionned at the desired point, but the beam shifts during a measurement. These faults in the beam location create measurement errors as shown by the calculations.

Figure 4 presents the variations of $V s$ as a function of $V 1$ for 3 different points over the buried track \#2. The values, as well as the slopes are different from one point to another. Potential measurements by the CCVC technique give only access to potential variations : it is possible to detect $\Delta V S$ as a function of $\Delta V 1$. Different slopes in the straight lines mean different $\Delta V S / \Delta V 1$. Hence the positionning of the beam must be as precise as possible when the error due to a $\Delta V 1$ on the measured value has to be calculated. The beam shift during a measurement also introduces errors, which can then be corrected with the help of the numerical solution.

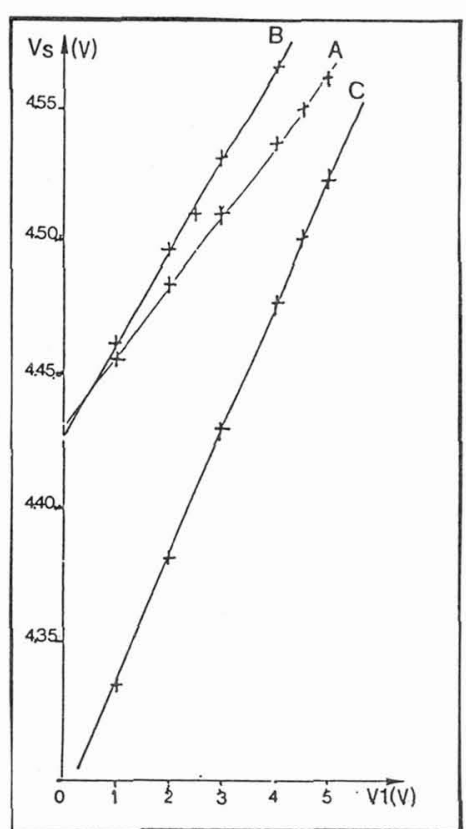

Fig. 4 : Computed values of Vs $\underline{\text { s. }}$. 1 (see fig.2) at the the points $A, B, C$

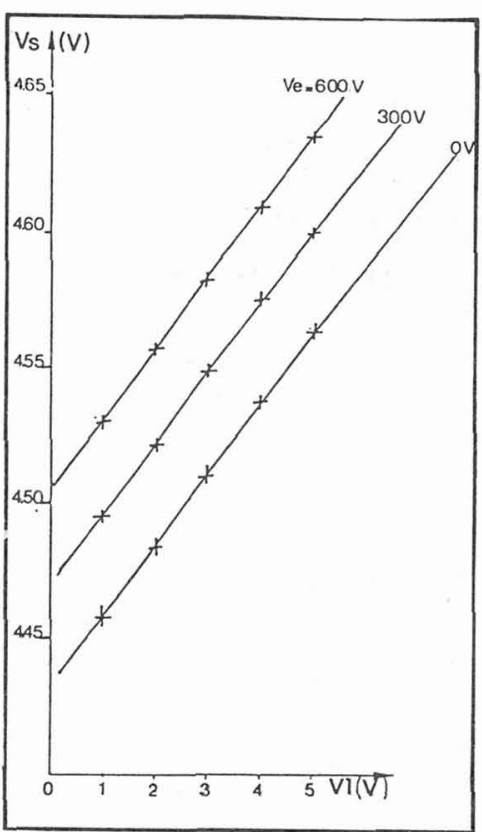

Fig._ 5 : Computed values of Vs vs. V1 for different values of $\overline{v e}$

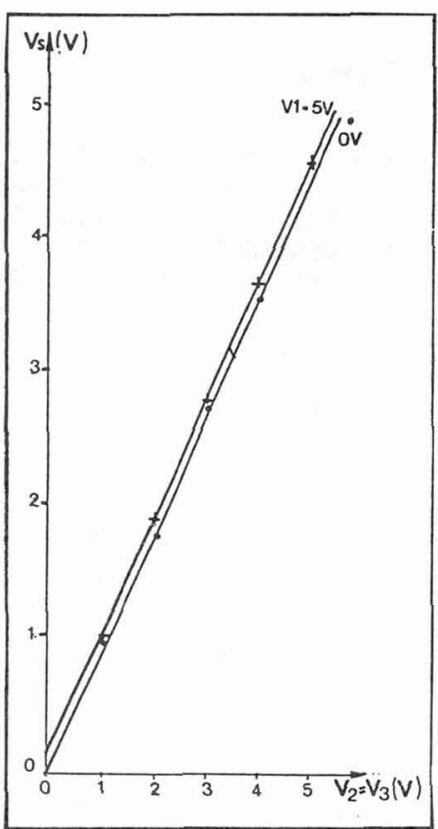

Fig._6 : Computed values of Vs vs. V2 and V3 (buried at tracks) for two values of v1 
In order to get a good voltage resolution, Ve has to be adjusted before every measurement by plotting the secondary emitted current vs; the potential of the filter grid ("S-curve"). The calculations show that the setting of ve to different values does not modify the slope of the plot (see Fig.5). Hence, the choice of ve does not act on the measured potential variations. However, the problem of the oxide charging by the extraction grid $/ 4 /$ has not been taken into account in the numerical simulation.

Figure 6 gives the variations of the surface potential as a function of the potential as a function of the buried tracks, for the two extremal values of $V 1(0-5 V)$. The constant value of the slopes of the two curves proves that the variations of the potential of the buried tracks, have no influence on the potential surface variations, created by the neighbouring tracks potential V1.

In fact, the numerical solution cannot give access to the potential actually measured, because of the capacitive coupling existing, between the buried track and the virtual electrode created at the interface by the electron beam, which could not be simulated. But the results shown on fig.6 prove that the influence of neighbouring and measured tracks are uncoupled. That is to say that the numerical solution can be used to determine the influence of the neighbouring potential on the measured value, and hence to yield the actual potential of the buried track.

\section{4 - ONㄷ느픔N}

A 2-D numercial potential simulation has been presented. Its application to improve the accuracy of electron beam testing of passivated IC's has been studied. We show that the position and the shift of the electron beam can widely create measurement errors, and that the potential of the extraction grid has no influence on the potential variation which can be measured by the CCVC technique. Though this model does not simulate the specific CCVC effect, the numerical results suggest that it can be used to correct the measured value and contribute to determine the actual potential of a buried track.

\section{REEFERENEEEES}

11/ GOERLICH S. - Duisburg University Thesis - VSI Reihe $9 \mathrm{Nr} 61$ (1986)

121 FREMONT H., TOUBOUL A., GOBLED D., DANTO Y. Proc. Colloque International "Reliability and Maintainability" Strasbourg - (Oct. 1988) - to be published.

13/ KOHLER R. : Private communication

14 NYE P., DINNIS A. - Scanning 7, pp 117-124 (1985) 